\title{
EDUCAÇÃO E CIDADANIA: UM ESTUDO SOBRE JOHN DEWEY
}

\author{
Silvia Cristina Soggio Del Monte ${ }^{1}$
}

\begin{abstract}
RESUMO: Este artigo tem como objetivo discutir a relação entre educação e cidadania na obra de John Dewey (1859-1952). Um dos mais aclamados teóricos educacionais do século XX, Dewey afirma que para o desenvolvimento de uma sociedade é preciso educar seus membros para que estes possam viver em harmonia, independente da classe social ou do grupo étnico, adquirindo através do conhecimento as habilidades necessárias para tomar decisões de forma autônoma e em confluência com as necessidades do grupo em que estão inseridos. Para refletir sobre essa relação, analisaremos algumas das obras centrais de Dewey especialmente "Democracia e Educação" (publicado originalmente em 1916) e "Experiência e Educação" (publicado originalmente em 1938) - à luz de investigações realizadas por especialistas na temática.
\end{abstract}

Palavras-chave: John Dewey; Educação; Cidadania; Autonomia.

ABSTRACT: The objective of this paper is to discuss the relation between education and citizenship that is within John Dewey's work (1859-1952). One of the most acclaimed of the twentieth century's educational theorists, Dewey says that a society to develop it is necessary to educate its members in order to make them live in harmony, no matter from which social class or ethnical group they are. It is also needed to teach them to acquire knowledge of the abilities that make people take decisions in an autonomous way, never forgetting to take into account the needs of the group in which they are in. To reflect about this relation between education and citizenship, we are going to go through some of Dewey's books - especially "Democracy and Education" (1916) and "Experience and Education" (1938) enlightened by some of the experts that are used to study Dewey's work.

Keywords: Keywords: Dewey; Education; Citizenship; Autonomy.

Esse artigo tem como objetivo discorrer sobre a relação entre a educação e a cidadania, sob o ponto de vista do filósofo educacional John Dewey, que escreveu a maioria de seus estudos no início do século XX: época em que os Estados Unidos da América do Norte estavam passando por uma crise financeira, com problemas de desemprego, falência de empresas, que foi desencadeada pela quebra da bolsa em 1929. Com isso, Cunha (2001) afirma que o americano comum ficou indiferente aos

\footnotetext{
1 Mestranda em Planejamento e Análise de Políticas Públicas pela Universidade Estadual Paulista “Júlio de Mesquita Filho" (UNESP) - Campus de Franca. Graduada em Letras pela PUC-SP e pelo Uni-FACEF.
} 
conflitos sociais, ao alastramento da corrupção e ao reacionarismo político e moral que tomaram conta do país, com um subsequente desmoronamento da imagem dos EUA como uma nação autossuficiente, devastando a autoconfiança dos cidadãos norte-americanos.

Ao escrever na época do New Deal, Dewey relembrou aos seus compatriotas as mensagens de cidadão liberal, de pró-atividade, de igualdade, e declarou que era possível se reorganizar através da educação, para a manutenção da liberdade e da democracia. Ao explanar suas teorias, apresentou ao mundo a lição do pragmatismo americano rumo a resultados racionalista-críticos, metodológicos e ético-políticos, conotados no sentido instrumentalista, como bem explicita Cambi (1999).

Pragmatismo que foi definido por Dewey (2007) como "extensão do empirismo histórico, mas com uma diferença fundamental, não insiste sobre os fenômenos antecedentes, mas sobre os fenômenos consequentes", o que significa dizer que a ação não nos remete a conhecer algo que já existiu ou aconteceu, mas a algo que está por existir e acontecer, a partir do momento em que o indivíduo executa a experiência. Experiência essa que não é restrita a si mesma, mas que transforma a vida da pessoa que a experimenta. É o agir sobre outro corpo e sofrer uma reação.

No plano humano, esse agir e reagir ganha uma maior amplitude, chegando à escolha, à preferência, à seleção que, em conjunto, apresentam a visão de mundo que esse indivíduo recortou dentre os conhecimentos apresentados a ele pelos adultos que o guiaram durante o processo de aprendizagem. A essa experiência inteligente, em que o pensamento participa, e que é reflexiva, a partir do momento que faz o ser humano perceber relações e continuidades que antes não eram percebidas, Dewey chama de "experiência educativa" e a equipara a educação, pois, para Dewey, "educar-se é crescer, não já no sentido fisiológico, mas no sentido espiritual, no sentido humano, no sentido de uma vida cada vez mais larga, mais rica e mais bela, e um mundo cada vez mais adaptado, mais propício, mais benfazejo para o homem" (TEIXEIRA, 1959, p. 7).

Para o estudioso, o homem é, desde o começo, "um animal que pergunta, que indaga, que busca - e que responde e acha" (TEIXEIRA, 1977, p. 67). Por este motivo, sua busca perpassa ações que têm como intenção melhorar sua estada no planeta, e para isso, utiliza-se de um método de causa e consequência para testar 
suas hipóteses. Dewey, afirma Anísio Teixeira (1977), acredita que toda ação humana que leva o indivíduo a adquirir um conhecimento dá-se por meio do método científico, assim como o próprio comportamento do homem, pois o instrumento dessa contínua dualidade entre predição e controle, oportunidade e aventura, acontece por meio de tentativa e erro, tentativa e acerto. O conhecimento é, portanto, o resultado de um processo de indagação que leva o indivíduo a adquirir ou aprender algo, como se ele tivesse descoberto por si próprio, através das experiências por ele vividas.

Teixeira (1977, p. 71) aponta ainda, que, para Dewey, "organismo e mundo não existem independentemente, desde que o 'mundo' se faz 'meio' de um ser vivo, isto é, o conjunto de condições pelas quais ele vive". O ser humano, portanto, apenas se apresenta como tal a partir do momento em que começa a viver em sociedade, então, é necessário a ele que desenvolva uma relação com os outros indivíduos de comportamento que permita a todos os membros do grupo coexistirem em harmonia. A educação foi uma das soluções encontradas para ensinar aos membros mais novos as tradições, os costumes e valores deste grupo. Outro motivo para a implementação da educação foi o de direcionar o comportamento dos jovens para o que seria o mais adequado para conviver em sociedade.

Se considerarmos a educação como processo por meio do qual os grupos sociais mantêm sua existência contínua, como afirma Dewey em seu livro Democracia e educação (1959), verificamos que a educação é o processo de renovação das significações da experiência, por meio da transmissão entre adultos e os mais jovens, em parte intencionalmente instituída para operar a continuidade social. Em Liberalismo e ação social (1970), Dewey completa que a educação inclui todas as influências que colaboram para a formação das atitudes e disposições que constituem os hábitos dominantes da mente e do caráter, de forma a tornar possível a liberdade efetiva e a oportunidade de crescimento individual a todos os indivíduos. Através dessas afirmações, o pensador conclui que o progresso da sociedade é uma união de esforços individuais aplicados com o objetivo de melhorar a vida do grupo em direção a relações sociais mais harmoniosas.

Com o objetivo de aprimorar a educação, os estudiosos do tema começaram a procurar meios para que esta fosse mais efetiva. Assim, a filosofia apresenta-se, de 
acordo com Dewey (1959, p. 359), como sendo "pensar o que aquilo que é conhecido requer de nossa parte - qual a atitude de correspondência que ele exige". É hipotética, ao passo que registra o que é possível e não fatos consumados, assim como todo ato de pensar. Seu valor aparece no momento em que se dispõe a analisar as dificuldades e sugerir métodos para nos avirmos com elas. Dewey conclui que filosofia é o pensamento que ficou consciente de si mesmo e generalizou seu lugar, valor e função na experiência.

Partindo do princípio de que a filosofia pensa a sociedade, e a educação é o meio pelo qual a sociedade transmite seus conhecimentos e costumes aos seus membros mais jovens, através de uma instituição baseada em interesses organizados e exigências institucionais, pode-se concluir que a educação é o "processo por intermédio da qual se podem operar as transformações necessárias, não permanecendo como mera hipótese do que é desejável, conseguimos justificar a afirmação de que a filosofia é a teoria da educação e esta a sua prática deliberadamente empreendida" (DEWEY, 1959, p. 365).

Ao discutir alguns princípios que Dewey preconizava, Manacorda (1996) salienta que o mesmo denunciou a separação entre ricos e pobres na escola, clamando que, para uma vida social justa, não poderia haver tal desmembramento da vida social, pois a escola é um instrumento em que se constrói o conhecimento através das experiências concretas de trabalho. Dessa forma, conclama que a finalidade de educar o indivíduo é o de prepara-lo para participar das mudanças que vieram a surgir na sociedade em que vive, ressaltando um ensino de laboratório, que pode levar o imaturo a aprender coisas que apresenta-lo-ão ao que ele pode vir a ser e não que o engessem no que ele já é. Manacorda (1996, p. 319) completa que "raramente um pensador mostrou uma tal coerência entre as premissas teóricas e as opções práticas".

Ao defender a ideia de liberdade de expressão na educação, Dewey (1971), também afirma que suas teorias só podem ser passíveis de interpretação em uma sociedade democrática, pois o princípio de respeito à liberdade individual e à decência e amabilidade das relações humanas intermeiam a sociedade e tornam possível, em larga escala, melhor qualidade de experiência. O papel do educador, então, faz-se necessário na aprendizagem de seu aluno no momento em que a 
maturidade de experimentação do adulto o coloca em uma posição de poder avaliar a experiência do mais jovem e verificar qual a direção que esta marcha, julgando-a e dirigindo-a.

Outro fator pelo qual Dewey acredita que o convívio em sociedade auxilia na educação dos mais jovens deve-se ao fato de os indivíduos participarem da mesma desde seu nascimento. Somos influenciados, em princípio pelo grupo familiar, posteriormente pela escola, amigos e, após adultos, pelos colegas de trabalho. $O$ que fica registrado no ser humano, dentre um mundo de pessoas e coisas é o que se fez e o que nos foi transmitido de atividades humanas, afirma o pensador; e, ignorar a participação dessa interação na construção das experiências, é trata-las "como algo que ocorre exclusivamente dentro do corpo de da mente das pessoas" (DEWEY, 1971, p. 31).

Com o propósito de colocar em prática suas crenças, em janeiro de 1896, fundou sua Escola Elementar da Universidade, na qual pretendia demonstrar que era possível colocar teoria e prática à prova, serem contestadas, criticadas, consolidadas e que, a partir da experimentação, pudessem evoluir novas verdades, afirma Frederick Eby (1976). Para tanto, seu plano foi o de não fornecer um esquema rígido de currículo pedagógico, mas um que englobasse métodos novos e mais naturais de se aprender. Os resultados das investigações nessa escola, que fez parte de uma corrente filosófica educacional chamada de progressista ou "nova escola", segundo Eby (1976), culminaram em seu livro A escola e a sociedade e, mais tarde, em um outro, intitulado Experiência e educação.

\section{O PAPEL DA EXPERIÊNCIA NO PROCESSO EDUCACIONAL}

Dewey tentou explicar sua teoria contrapondo-a com o estilo de educação que vigorava em sua época, e que recebeu o nome de educação tradicional esquematizada por uma imposição de cima para baixo e de fora para dentro; apresentando distância entre o que se impõe e os que sofrem a imposição, com aspectos muitas vezes brutais - e as características de seus questionamentos, que a seu ver, eram mais coerentes com o processo de aprendizagem. Suas ideias encontravam-se com as de um grupo de pensadores da educação, tornando-se 
conhecidas como educação progressiva - marcada pela aquisição de conhecimento como meio para atingir fins que respondem a apelos diretos e vitais dos alunos, aproveitando-se ao máximo as oportunidades presentes. Ou seja, o que John Dewey preconizava era o modelo de educação baseado na experiência do estudante, que ele nomeia de imaturo, como princípio norteador do processo de ensino-aprendizagem, autorizando esses indivíduos a exercitarem sua expressão e o cultivo da individualidade.

Todo processo educacional, como verifica Fott (2009) em seu estudo sobre a influência mútua entre democracia e educação, leva o indivíduo a um crescimento, a aquisição de novos conhecimentos, sejam eles acadêmicos ou não, e que estão conectados ao modo como os seres humanos modelam suas atitudes em grupo e que são cruciais no processo de formação de significado para cada pessoa. Deste modo, o crescimento deve ser a meta final da educação uma vez que requer liberdade para adquirir a capacidade de saber fazer as escolhas, sejam elas acertadas ou não.

Dewey acreditava que o indivíduo aprende através de experiências, como já dissemos, e que essas experiências podem ser adquiridas através de uma relação social pessoal baseada em contatos mais íntimos e numerosos entre o imaturo e pessoas mais amadurecidas, com o objetivo de dar ênfase à liberdade do aluno. As experimentações advindas dessa liberdade podem assumir dois aspectos: ser agradável ou desagradável. Esses aspectos irão nortear a aprendizagem desse indivíduo sempre que tal assunto for trazido à tona pelos educadores, portanto, deve-se levar em conta como o efeito dessa experiência dar-se-á no imaturo.

No sistema educacional apresentado por Dewey (1971) se faz necessária uma conexão da educação com a experiência. Tal conexão deve ser fiel aos seus princípios e ter em vista constantemente seus elementos; armando sistemas de educação que: 1) subordinem as condições objetivas àquelas que se encontrem no indivíduo a ser educado; 2) promovam a interação entre o estudante, a sociedade, a família e a escola. Portanto, de acordo com essa perspectiva:

Quando se afirma que as condições objetivas são as que estão dentro do poder do educador de ordenar e regular, está claro que isto subentende que lhe cabe o dever de determinar o ambiente, que, entrando em interação com as necessidades e capacidades 
daqueles a que vai ensinar, irá criar a experiência educativa válida. [...] a responsabilidade, portanto, de selecionar as condições objetivas importa na responsabilidade de compreender as necessidades e capacidades dos indivíduos que estão aprendendo em dado tempo (DEWEY, 1971, p. 38-39).

Quando o professor consegue discernir entre seus alunos quais os interesses e capacidades de cada um, pode preparar uma aula que os estimule em conjunto, mas de modo que atinja a todos de maneira especial, para que o conhecimento transmitido seja apreendido de maneira útil e contextualizada com as vivências individuais dos estudantes.

\section{Autoridade e controle social no ambiente escolar}

John Dewey (1971, p. 48) acredita que o "controle das ações individuais é efetuado pela situação global em que os indivíduos se acham envolvidos e em que participam e atuam como partes componentes e cooperativas", o que significa dizer que, para o pensador, pode-se controlar as atitudes das pessoas por meio de como a sociedade em que este está inserido estrutura-se e comporta-se, pois, como já vimos anteriormente, todos nascemos inseridos em um grupo.

$\mathrm{Na}$ escola não é diferente. Uma escola bem organizada consegue se impor sobre o indivíduo no curso das atividades propostas e nas situações educacionais criadas, utilizando-se do controle e da autoridade quando se faz necessário. $E$ tais controle e autoridade serão sempre postos em sintonia com o interesse do grupo e não como exibição do poder pessoal, afirma Dewey (1971).

O filósofo apresenta como fonte primária de controle social a própria natureza do trabalho, que necessita do comprometimento social. Todos os indivíduos devem contribuir com algo para a sociedade, assim como devem ser responsáveis por suas ações individuais perante o grupo. Para que o compromisso e a responsabilidade sejam efetivos, a comunidade escolar precisa se organizar e planejar com antecedência, pois, como já lembramos, o educador é responsável pelo conhecimento que irá ensinar a seus alunos, de forma que todos tenham a possibilidade de contribuir e partilhar o que foi aprendido. 
Algumas vezes, afirma Dewey (1971), haverá casos de alunos que chegam à escola vítimas de condições injuriosas fora da escola, as quais os fizeram passivos, indóceis, que se recusam a contribuir. Nesse caso, o educador deve encontrar o melhor modo de inserir esse jovem no ambiente escolar, esforçando-se para descobrir a origem de tal comportamento e procurar minimizar essa característica dentro da escola, para que o ambiente na escola volte a se estabilizar.

\section{Liberdade dentro da escola}

Mesmo havendo controle e autoridade como características intrínsecas ao ambiente escolar, ainda há espaço para que a liberdade floresça dentro dela.

Dewey (1971, p. 59) diz que "a única liberdade de importância duradoura é a da liberdade da inteligência, isto é, liberdade de observação e de julgamento com respeito a propósitos intrinsecamente válidos e significativos". Portanto, ao mesmo tempo em que a escola molda o comportamento do indivíduo para que este consiga se colocar na sociedade, de acordo com os costumes praticados pelo grupo, a instituição também libera o aluno a se libertar e expressar sua individualidade, de modo que se integre efetivamente os conhecimentos apreendidos nas matérias ministradas por seus professores à sua mente e seu caráter em desenvolvimento, favorecendo, com isso, o verdadeiro processo de aprendizagem.

Se a escola conseguir atender a todos esses requisitos apresentados por John Dewey em seu livro Experiência e educação, conseguirá atingir plenamente o seu fim que é o da formação da capacidade de domínio de si mesmo.

Nessa mesma obra, Dewey (1971) apresenta quais são as características necessárias aos imaturos para alcançar o domínio pessoal. O primeiro conceito é o de propósito. Definido como um fim em vista, uma previsão de consequências operada pela inteligência e que requer, em primeiro lugar, observação das condições objetivas e das circunstâncias. Em segundo lugar, o indivíduo deve compreender a significação do propósito que está prestes a efetuar e, finalmente julgar se é possível que tal desejo/propósito possa realizar-se.

Transpondo essa definição para o contexto educacional, o filósofo afirma que esse é o ponto de partida para conseguir ensinar algo a alguém. Acrescenta que, 
para os jovens, aprenderem os conteúdos ensinados na escola, melhor do que força-los a aprender é cultivar o interesse dos mesmos. Para isso, é mister utilizar o conhecimento que trazem de casa, pois, quando o

[...] professor a par, pela observação e estudo inteligente, das capacidades, necessidades e experiências passadas dos que vão estudar, e, segundo, permitir que a sugestão feita se desenvolva em plano e projeto por meio de sugestões adicionais trazidas pelos membros do grupo e por eles organizadas em um todo. O plano será, então, resultado de um esforço de cooperação e não algo imposto. (DEWEY, 1971, p. 71)

O desafio, então, será o de, no exercício de sua função, o professor selecionar os temas, dentro de uma gama de experiências, que tenham a possibilidade de suscitar novos problemas; que serão estimulados pela observação e pelo julgamento, e que ampliarão a área de experiências posteriores desses alunos, afirma Dewey (1971). O educador deve, ainda, ter um olhar voltado para o futuro, utilizando-se de conteúdos disponíveis no presente, incitando o aluno a aprender, estimulando-o a pensar.

Ao utilizar-se das experiências dos imaturos para construir o conhecimento a ser desenvolvido na escola, apresentamos a relação existente entre causa e consequência, ou seja, fica mais transparente para os jovens que a educação não está restrita aos bancos escolares, mas pode fundir-se com a vida cotidiana. Nessa fusão, é possível ampliar os horizontes das experiências vividas e expandi-las. Transformando-os em cidadãos racional-críticos, ético-políticos que, ao indagar os fatos da realidade, encontrem respostas que possam confirmar ou refutar suas hipóteses e dirimir dúvidas advindas de experiências vivenciadas pelos estudantes.

\section{EDUCAÇÃO: FATOR DETERMINANTE PARA A DEMOCRACIA}

Dewey afirma e reafirma em seus livros que a escola é uma sociedade embrionária, onde o imaturo irá aprender a se apresentar dentro da sociedade em que vive e, por esse motivo, a escola deve desenvolver um método de ensino que cative esse indivíduo. 
Dizer que a educação é uma função social que assegura a direção e o desenvolvimento dos imaturos, por meio de sua participação na vida da comunidade a que pertencem, equivale, com efeito, a afirmar que a educação variará de acordo com a qualidade da vida que predominar no grupo (DEWEY, 1971, p. 87).

Um grupo, seja ele qual for, sempre terá interesses que dizem respeito a todos os indivíduos que o compõe e apresenta certa posição de interação e reciprocidade cooperativa com outros grupos, compartilhando conscientemente interesses, apesar de continuarem existindo vários e livres pontos de contato com outras modalidades de associação, afirma o filósofo em seu livro Democracia e Educação.

Democracia, como governo de todos e para todos é uma teoria que Dewey acredita ir contra a natureza individualista humana, já que esse tipo de teoria isolou o fator 'externo' das interações que produzem os fenômenos sociais, que rivaliza com outro que isolou o fator 'interno' humano, ou seja, Dewey (1970), verifica que o comportamento humano é reflexo de movimentos sociais em um dado tempo, dentro de um determinado grupo, mas que buscam uma satisfação individual em cada experiência vivida. E cada experiência do ser humano opera em uma multidão de diferentes condições ambientais, que determinam as consequências e a importância e valor social das tendências comportamentais de cada época.

Seguindo o raciocínio de participação dos indivíduos na vida da comunidade, Dewey (1959) afirma que quanto mais estímulos são apresentados aos menos favorecidos do grupo, mais estes tendem a se converter e a se tornar caprichosos, impulsivos e propensos à pesquisa e ao pensamento. As relações do homem com seu trabalho são uma constatação dessa afirmação, pois notamos que o trabalhador coloca seu interesse inteligente naquilo que estiver fazendo, principalmente se seu interesse e aptidão forem de encontro com a atividade que está realizando. Por isso:

Não podemos continuar com a ideia de que a natureza humana, quando deixada a si mesma, quando libertada de restrições arbitrárias exteriores, tenderá a produzir instituições democráticas que funcionam com êxito. [...] Temos de ver que democracia significa a crença de que deve prevalecer a cultura humanística; devemos ser francos e claros em nosso reconhecimento de que a proposição é 
uma proposição moral, como qualquer ideia referente a dever ser (DEWEY, 1970, p. 212, grifo do autor).

A educação, portanto, deve ser apoiada pela moral, para que o bem da sociedade prevaleça sobre a vontade de se obter ganho individual, e, por esse motivo, deve-se reforçar o caráter moral do ensino. Comprometida com o social, a educação deve usar seus poderes para estabelecer condições para que todos os indivíduos tenham igual liberdade, ou como aponta Cunha (2001), tenham direito de lutar por um mundo melhor, mais justo e menos desigual, no que tange os direitos legalmente constituídos e a distribuição de bens materiais.

\section{O ideal democrático e os objetivos da educação}

Para Dewey (1959), um objetivo educacional de alicerçar-se nas atividades e necessidades intrínsecas (inclusive os instintos inatos e os hábitos adquiridos) do indivíduo que vai ser educado. Tal objetivo deve ser passível de converter-se em método de cooperação com a atividade daqueles que recebem a instrução, visando a expansão e organização de suas aptidões pois o sentido da verdadeira educação é o de ampliar a perspectiva do espírito, estimulando as pessoas a tomar em conta mais consequências, através de uma observação de meios e recursos mais vasta e flexível.

Ao se valorizar a aptidão, podemos formar um cidadão melhor e mais eficiente para seu grupo, já que, como verifica Dewey, o interesse e a vocação do indivíduo pela tarefa a ser realizada é de grande importância para o processo de execução e o desfecho da empreita, como notamos neste trecho:

Quem reconhecer a importância do interesse não presumirá que todos os espíritos funcionam do mesmo modo pela razão de acontecer-lhes terem o mesmo professor e o mesmo compêndio. As atitudes e os modos de "ataque" e de reação variam com a sugestão específica do mesmo material e essa sugestão também varia de acordo com a diferença das aptidões naturais, da experiência passada, do modo de vida, etc. (DEWEY, 1959, p. 142). 
Como já foi mencionado anteriormente, Dewey acredita que as propostas da "nova escola" são possíveis de serem adotadas principalmente em um modelo de governo que seja democrático, para que possam ser garantidos os direitos dos imaturos de expressão e liberdade de pensamento. Mas o que significa democracia para o pensador?

Alguns elementos que compõem uma sociedade democrática, de acordo com Dewey (1959, p. 93), são, primeiramente,

[...] não só mais numerosos e variados pontos de participação do interesse comum, como também maior confiança no reconhecimento de serem, os interesses recíprocos, fatores de regulação e direção social. Em segundo, apresenta-se não só uma cooperação mais livre entre os grupos sociais [...] como também a mudança dos hábitos sociais - sua contínua readaptação para ajustar-se às novas situações criadas pelos vários intercâmbios.

Para que as sociedades democráticas usufruam mais completamente dessa possibilidade de readaptação, cooperação e interesse comum, seus governantes necessitam de um meio regulador, que dirija os indivíduos que a constituem, de maneira que se enquadrem e contribuam para a mesma. Nesse contexto, a escola vem como um instrumento ideal para ser o guia dos cidadãos mais jovens.

Seja porque um governo que se funda no sufrágio popular não pode ser eficiente se aqueles que o elegem e the obedecem não forem convenientemente educados; ou porque "uma democracia é mais que uma forma de governo; é primordialmente, uma forma de vida associada, de experiência conjunta e mutuamente comunicada" (DEWEY, 1959, p. 93). O pensador acredita na força da instrução acadêmica como forma de demonstrar ao cidadão aos costumes comportamentais e intelectuais da sociedade em que vive.

O objetivo da educação em uma democracia pode ser sintetizado, então, pela busca de se libertar o pensamento e a criatividade de seus membros, como forma de fazê-los descobrir suas aptidões, ao mesmo tempo em que os educadores direcionam, moldam e guiam suas ações, de modo que possam se relacionar com o resto do grupo e se reconheçam nele. 
Dewey (1959) teoriza sobre o valor da educação para a sociedade e, afirma que uma de suas premissas é a de que não podermos estabelecer uma hierarquia de estudos, pois é inútil tentar dispor as matérias de estudo em uma ordem que começasse com a de menor valor e acabasse com as de maior, uma vez que cada uma tem uma função insubstituível e única. A prova de que uma coisa é boa dentro da escola está no fato de o aluno "responder" a ela, e sua resposta é o uso, mostrando que a matéria tem função em sua vida, ou seja, aguçou seu interesse e suas aptidões.

Para Dewey (1959) uma vez que o indivíduo foi educado e encontrou seu lugar na sociedade através de uma colocação profissional, baseada na recompensa de seus estudos e de suas aptidões, é de bom grado que este possa usufruir de um guia livre no exercício da atividade prática e faça com que o lazer seja sua recompensa pela aceitação da responsabilidade dos serviços práticos, ou seja, os membros do grupo que se adaptam ao mesmo podem beneficiar-se de momentos de lazer, nos quais a individualidade e a liberdade de expressão tomam espaço, pois, para Dewey (1959, p. 317), "o importante é que o fato seja apreendido em suas conexões sociais - em sua função com a vida".

\section{Indivíduo vs. Democracia}

Quando pensamos em democracia, salta-nos logo o conceito de governo de todos e para todos. Porém, dentro desse "todos" existe um sem número de indivíduos com suas respectivas personalidades e necessidades. Portanto, é preciso que todos os membros do grupo ajam de forma a viabilizar a harmonia dentro deste e que todos se guiem pela busca do interesse comum. $O$ individualismo rompe conscientemente com os diversos setores da vida em sociedade. Fechado em si mesmo, completamente alheios às ideias, propósitos e desejos das outras pessoas, a pessoa esquece de que está inserido em um mundo público e comum a todos. "quando se nega a qualidade social das operações mentais individualizadas, surge o problema de encontrar conexões que unam o indivíduo a seus iguais" (DEWEY, 1959, p. 328). 
Respeitar o espaço do outro também apresenta-se como um dos direcionamentos que a escola deve fornecer aos seus estudantes, já que esta é uma sociedade em miniatura ou embrionária, como diz Dewey (1971).

O termo liberdade/individualismo, como conceitua Dewey (1959, p. 333), significa o papel desempenhado pelo ato de pensar - que é pessoal - no aprendizado: significa iniciativa intelectual, independência na observação, invenção judiciosa, previsão de consequências e engenho na sua adaptação. Então, a individualidade na educação tem uma significação dupla: de um lado temos o estudante com sua personalidade, suas ideias, seus sonhos, sua realidade particular; por outro, existe uma diversidade de personalidades, ideias, sonhos, realidades que diferem de um indivíduo para outro. Com isso, o papel da educação é valorizar as particularidades intrínsecas a cada pessoa, deixando-as livres intelectualmente, para que possam pensar por si mesmas, e contribuam para a sociedade em que vivem através de suas aptidões e interesses ao mesmo tempo em que respeitem o interesse comum em detrimento de seu próprio interesse individual.

\section{CONSIDERAÇÕES FINAIS}

Pode-se verificar que a educação tem um papel central na história quando o assunto é a inserção dos indivíduos que compõem a sociedade no grupo, seja utilizando o método separatista entre as classes sociais, seja como preparação de mão-de-obra especializada para trabalhar no campo ou nas fábricas. Mais recentemente, com o advento da democracia moderna, emergiram teorias de uma educação igualitária para todos, e nessa corrente inclui-se nosso filósofo da educação, John Dewey.

Em resumo, o que apontamos nas páginas anteriores é que a filosofia da educação proposta por Dewey é contra a segregação social nas escolas, defende a liberdade de expressão e a individualidade dentro da escola, como parte do processo de experimentação para a aquisição de novos conhecimentos. Defende, também, o poder da escola como guia, já que esta é uma sociedade em miniatura, 
pura em que os imaturos podem cometer erros e até extrapolar os limites com a intenção de criar novos conceitos.

O papel da democracia nesse contexto apresenta-se como o modo de governo propício para o florescer de indivíduos pensantes e críticos, formados por um currículo pedagógico que possibilite cultivar o interesse intelectual, de acordo com as aptidões e propósitos de cada um, desde que sejam observadas as regras das boas relações sociais.

Em suma, John Dewey e suas teorias educacionais refletem os ideiais da sociedade que vive no século XXI, abrindo possibilidades para que seus cidadãos participem consciente e criticamente da mesma.

\section{REFERÊNCIAS BIBLIOGRÁFICAS}

CAMBI, Franco. História da pedagogia. São Paulo: Editora UNESP, 1999. 701p.

CUNHA, Marcus Vinicius. John Dewey: filosofia, política e educação. Perspectiva, Florianópolis, v 19. n 2., jul/dez 2001. Disponível em

$<$ https://periodicos.ufsc.br/index.php/ perspectiva /article/view/10235>. Acesso em 11 abr. 2014.

DEWEY, John. Experiência e educação. São Paulo: Ed. Nacional, 1971. 97p.

. Democracia e educação: introdução à filosofia da educação. São Paulo: Companhia Editora Nacional, 1959. 415 p. (Coleção atualidades pedagógicas, v. 21).

. O desenvolvimento do pragmatismo americano. Revista Scientia e Studia, São Paulo, v. 5., 2007. Disponível em <http://www.scielo.br/scielo.php?pid=S167831662007000200006\&script=sci arttext\#end1>. Acesso em 13/04/2014.

- Liberalismo, liberdade e cultura. Trad. Anísio Teixeira. São Paulo: Companhia Editora Nacional, 1970. 261 p.

EBY, Frederick. História da educação moderna: teoria, organização e práticas educacionais. 2. Ed. Porto Alegre: Ed. Globo; Brasília: Instituto Nacional do Livro, 1976. $633 \mathrm{p}$. 
FOTT, David. John Dewey and the Mutual Influence of Democracy and Education. The Review of Politics, Cambridge, v. 71, 2009. Disponível em <http://www.jstor.org/stable/ 25655782 >. Acesso em: 11 abr. 2014.

MANACORDA, Mario Alighiero. História da educação: da Antiguidade aos nossos dias. 5. Ed. São Paulo: Cortez, 1996. 382 p.

TEIXEIRA, Anísio S. Educação como reconstrução da experiência. In: DEWEY, John. Vida e educação. Trad. Anísio Teixeira. 5. São Paulo: Companhia Editora Nacional, 1959. 174 p. (Coleção Atualidades pedagógicas, v 76).

Educação e o mundo moderno. 2. São Paulo: Companhia Editora Nacional, 1977. 245 p. 